OPEN ACCESS

Edited by:

Ivan Baccelli,

Consiglio Nazionale Delle Ricerche

(CNR), Italy

Reviewed by:

Manuel Benedetti,

Department of Biotechnology,

University of Verona, Italy

Daniela Pontiggia,

Sapienza Università di Roma, Italy

*Correspondence:

Mario Serrano

serrano@ccg.unam.mx

Specialty section:

This article was submitted to

Plant Microbe Interactions,

a section of the journal

Frontiers in Microbiology

Received: 30 April 2018

Accepted: 27 June 2018

Published: 17 July 2018

Citation:

Ferreira-Saab $M$, Formey $D$, Torres $M$

Aragón W, Padilla EA, Tromas $A$,

Sohlenkamp C, Schwan-Estrada KRF

and Serrano M (2018) Compounds

Released by the Biocontrol Yeast

Hanseniaspora opuntiae Protect

Plants Against Corynespora cassiicola

and Botrytis cinerea.

Front. Microbiol. 9:1596.

doi: 10.3389/fmicb.2018.01596

\section{Compounds Released by the Biocontrol Yeast Hanseniaspora opuntiae Protect Plants Against Corynespora cassiicola and Botrytis cinerea}

\author{
Mariana Ferreira-Saab ${ }^{1,2}$, Damien Formey ${ }^{1}$, Martha Torres ${ }^{1}$, Wendy Aragón ${ }^{1}$, \\ Emir A. Padilla ${ }^{1}$, Alexandre Tromas ${ }^{1}$, Christian Sohlenkamp ${ }^{1}$, Kátia R. F. Schwan-Estrada ${ }^{2}$ \\ and Mario Serrano ${ }^{1 *}$ \\ ${ }^{1}$ Centro de Ciencias Genómicas, Universidad Nacional Autónoma de Mexico, Cuernavaca, Mexico, ${ }^{2}$ Departemento de \\ Agronomia, Universidade Estadual de Maringá, Maringá, Brazil
}

Plant diseases induced by fungi are among the most important limiting factors during pre- and post-harvest food production. For decades, synthetic chemical fungicides have been used to control these diseases, however, increase on worldwide regulatory policies and the demand to reduce their application, have led to searching for new ecofriendly alternatives such as the biostimulants. The commercial application of yeasts as biocontrol agents, has shown low efficacy compared to synthetic fungicides, mostly due to the limited knowledge of the molecular mechanisms of yeast-induced responses. To date, only two genome-wide transcriptomic analyses have characterized the mode of action of biocontrols using the plant model Arabidopsis thaliana, missing, in our point of view, all its molecular and genomic potential. Here we describe that compounds released by the biocontrol yeast Hanseniaspora opuntiae (HoFs) can protect Glycine max and Arabidopsis thaliana plants against the broad host-range necrotrophic fungi Corynespora cassiicola and Botrytis cinerea. We show that HoFs have a long-lasting, dose-dependent local, and systemic effect against Botrytis cinerea. Additionally, we performed a genome-wide transcriptomic analysis to identify genes differentially expressed after application of HoFs in Arabidopsis thaliana. Our work provides novel and valuable information that can help researchers to improve HoFs efficacy in order for it to become an ecofriendly alternative to synthetic fungicides.

\footnotetext{
Keywords: Biocontrol agent, elicitors, Hanseniaspora opuntiae, Corynespora cassiicola, Botrytis cinerea, Glycine max, Arabidopsis thaliana, plant defense responses
}

\section{INTRODUCTION}

Of all food produced for human consumption, every year 1.3 billion tons are lost or wasted (http://www.fao.org). Only during post-harvest, 25 to $50 \%$ of the production can be lost due to plant diseases induced by microorganisms and by suboptimal handling and storage conditions (Nunes, 2012). Fungal species are responsible for most of these losses, including the genera Alternaria, Aspergillus, Botrytis, Fusarium, Geotrichum, Gloeosporium, Penicillium, Mucor, and 
Rhizopus (Barkai-Golan, 2001; Dean et al., 2012). The importance of fungi-related disease can be exemplified by mentioning that if producers could avoid the damages associated to fungi in the five most important crops, 600 million people could be fed each year (Fisher et al., 2012). For decades, fungicides have been used to control fungi-induced diseases. However, an increase in worldwide regulatory policies and the demand to reduce their application, due to potential harmful side effects to the environment and to humans, have led to searching for new ecofriendly alternatives. One of these alternatives is biostimulants, which are defined as a naturally-occurring chemicals or microorganisms that enhance plant development, abiotic, and biotic stress tolerance and/or crop quality traits ( $\mathrm{Du}$ Jardin, 2015).

Biostimulants that protect the plant against pathogens can be classified as elicitors and biocontrol agents (BCAs). Microorganisms such as bacteria and yeast, have been used as BCAs to control herbivores and several plant pathogens. For instance, bacteria from the genera Bacillus, Pseudomonas, and Pantoea have been used to control mold-produced fungi, mainly by the production of antibiotics (Nunes et al., 2002; Cirvilleri et al., 2005; Ren et al., 2013). However, even if some of them are already used in the field, several concerns arrise, in particular the possible development of resistance in the pathogens. Nowadays, one alternative is to use yeast as BCAs, since they are antagonistic microorganisms that can grow under adverse environmental conditions without special nutrients requirements and do not produce compounds harmful to human health (Liu et al., 2013). The basis of the antagonistic properties of yeast against pathogens has been previously described and includes: competition for nutrients, $\mathrm{pH}$ changes on the plant surface, production of ethanol and biosynthesis of killer toxins called mycocins (Hatoum et al., 2012). Nevertheless, despite all these beneficial traits, the commercial application of yeast in the field as BCAs has shown an inconsistent efficacy compared to synthetic fungicides, mostly due to the lack of knowledge of the molecular mechanisms behind yeast-induced plant defense responses (Massart et al., 2015).

On the other hand, elicitors are chemical molecules that activate the plant defense responses, and include microbe- and damage-associated molecular patterns (MAMPs and DAMPs), polypeptides, glycoproteins, lipids, proteins, glycolipids, and oligosaccharides (Katagiri and Tsuda, 2010; Maffei et al., 2012; Hael-Conrad et al., 2015; Yin et al., 2016). Once the elicitors are perceived by the plant, the first line of defense, called plant innate immunity is activated. During this initial defense mechanism, the production of reactive oxygen species (ROS), calcium influx, MAPK-dependent signaling cascades, localized cell death and transcriptional induction of the early defense response genes are activated (Katagiri and Tsuda, 2010; Tsuda and Somssich, 2015). After the induction of innate immunity at the local infected tissue, secondary defense responses are triggered, including salicylic the acid- (SA), jasmonic acid- (JA),

Abbreviations: HoFs, Hanseniaspora opuntiae-Filtrates; hpt, hours post treatment; hpi, hours post inoculation; PDA, potato dextrose agar media; YNB, yeast nitrogen base media. and ethylene- (ET) dependent signaling pathways, that lead to the activation of systemic acquired resistance (SAR) at noninfected distal parts of the plant (Boller and Felix, 2009; RobertSeilaniantz et al., 2011). The combined effect of the local and systemic defense responses, can block efficiently the disease inflicted by non-adapted pathogens (Craig et al., 2009). Due to these characteristics, elicitors have the potential to be used in agriculture as alternative to fungicides. However, to do so, it is necessary to better characterize the molecular changes induced by elicitors in order to optimize its application and activity in the field (Wiesel et al., 2014).

Molecular characterization of the plant-microbe interactions has been greatly benefitted from the technical advances in areas including metabolomics, proteomics, genomics and bioinformatics, in particular using Arabidopsis thaliana as a model. For example, this has led to novel conceptual advances in the understanding of the molecular basis of plant-pathogen interactions (Mishra et al., 2017). Importantly, these advances also saw the dawn of a series of potential applications that could impact crop protection (Bhadauria, 2016). During the last decade, several genome-wide transcriptomic analyses have been used to characterize the mode of action of BCAs (Massart et al., 2015). However, strangely, many of these analyses have been performed under in-vitro conditions and only two of them were characterized using the interaction Arabidopsis thaliana-BCAs as pathosystem (Feng et al., 2012; Morán-Diez et al., 2012).

\section{HoFs}

In this report, we show that compounds released by the biocontrol yeast Hanseniaspora opuntiae, henceforth identified as H. opuntiae-Filtrates (HoFs), have the potential to protect against the broad host-range necrotrophic fungi Corynespora cassiicola and Botrytis cinerea. In order to better understand the molecular basis of HoFs-induced resistance, we characterized its activity in the well-described pathosystem Arabidopsis thaliana-Botrytis cinerea. We determined that HoFs can protect Arabidopsis thaliana against the necrotrophic fungus Botrytis cinerea. HoFs can induce the defense response in a dose-dependent manner. Additionally, performing a genome-wide transcriptomic analysis (RNA-seq), we identified that the genes differentially expressed upon application of HoFs, differ from those induced by other previously-described BCAs. This valuable information might help to reveal the molecular mechanisms behind HoFs-induced defense and can help researchers to improve their efficacy and to become an ecofriendly alternative to pesticides.

\section{MATERIALS AND METHODS}

\section{Purification of HoFs}

Hanseniaspora opuntiae CCMA 0760, was provided by the laboratory of Physiology and Genetics of the Federal University of Lavras, Brazil. Hanseniaspora opuntiae was grown in YNB (Yeast Nitrogen Base) media for 10 days in a $12 \mathrm{~h}$ light $/ 12 \mathrm{~h}$ dark cycle at $24^{\circ} \mathrm{C}$. At the end of the growth period, the culture media was centrifuged at $10,000 \mathrm{rpm}$ for $20 \mathrm{~min}$ and the supernatant was filtered using $0.22 \mu \mathrm{m}$ filters. Filtered material (HoFs) was diluted at the indicated concentration with distilled sterile water. In order 
to have a weight/volume concentration, the filtrated material (100\%) was lyophilized and the concentration was determined $(8.45 \mathrm{mg} / \mathrm{ml})$.

\section{In-Vitro Inhibitory Assay of Corynespora cassiicola and Botrytis cinerea Growth}

Corynespora cassiicola growth and preparation of spore suspension were performed as previously described (Soares et al., 2009). Botrytis cinerea strain BMM was provided by Brigitte Mauch-Mani (University of Neuchatel, Switzerland). Botrytis cinerea growth and preparation of spore suspension were performed as previously described (L'Haridon et al., 2011). For the inhibitory assay, a spore suspension of Corynespora cassiicola $\left(3 \times 10^{5}\right.$ spores $\left.\mathrm{ml}^{-1}\right)$ or Botrytis cinerea $\left(5 \times 10^{4}\right.$ spores $\mathrm{ml}^{-1}$ ) was placed at the center of a Petri dish containing potato dextrose agar media (PDA) supplemented with 20,30, 40, and $50 \% \mathrm{HoFs}$ and incubated at $22^{\circ} \mathrm{C}$ for $72 \mathrm{~h}$. Inhibition was evaluated by measuring the diameter of the mycelium on the dish. The experiment was carried out in a completely randomized design (CRD), with five replicates for each treatment. Botrytis cinerea spore germination assay was performed as previously described (Hael-Conrad et al., 2015). Pictures were taken at 24 hpi with a digital camera attached to a Leica DMR microscope with bright-field settings. Images of growing Botrytis cinerea hyphae were analyzed using Image J version $1.51(\mathrm{NIH})$.

\section{Plant Maintenance}

Glycine max plants cultivar INT 6100, were grown under greenhouse conditions on pots containing non-autoclaved soil. Arabidopsis thaliana seeds were grown on a pasteurized soil mix of humus and perlite (3:1), kept at $4^{\circ} \mathrm{C}$ for 2 days and then transferred to the growth chamber. Plants were grown during 4 weeks in a $12 \mathrm{~h}$ light $/ 12 \mathrm{~h}$ dark cycle with $60-$ $70 \%$ of relative humidity, at a day temperature of $20-22^{\circ} \mathrm{C}$ and a night temperature of $16-18^{\circ} \mathrm{C}$. Arabidopsis thaliana ecotype Columbia-0 (Col-0) was obtained from the Nottingham Arabidopsis Stock Centre (Nottingham, UK).

\section{HoFs Treatment and Corynespora cassiicola or Botrytis cinerea Plant Inoculation}

Corynespora cassiicola infection procedure and disease severity quantification were performed as previously described (Soares et al., 2009). Glycine max plants were grown until the V4 developmental stage (third fully expanded trifolium) and sprayed until saturation with $20 \%$ HoFs or mock (distilled sterile water) every 7 days, for 4 weeks. $24 \mathrm{~h}$ after the last treatment, plants were infected with a Corynespora cassiicola spore suspension $(3 \times$ $10^{5}$ spores $\mathrm{ml}^{-1}$ ) and $120 \mathrm{~h}$ post infection (hpi) disease severity was measured determining the minimum and maximum limits and the intermediate levels of the scale, according to WeberFechner's stimulus-response law, as previously described (Soares et al., 2009). Botrytis cinerea infection procedure and lesion size measurement were performed as previously described (L'Haridon et al., 2011). Four-week-old Arabidopsis thaliana plants were sprayed until saturation with $50 \%$ HoFs or mock (YNB) for $24,48,72,96$, or $120 \mathrm{~h}$ post treatment (hpt), as indicated in the Figure legends. After this time, $3 \mu \mathrm{l}$ droplets containing
Botrytis cinerea spore suspension $\left(5 \times 10^{4}\right.$ spores $\left.\mathrm{ml}^{-1}\right)$ were applied. Infection symptoms were evaluated $72 \mathrm{hpi}$ by measuring lesion size $(\mathrm{cm})$. For the dose-response assay, plants were pretreated with the indicated concentration HoFs and evaluated at $72 \mathrm{hpi}$. For the systemic assay, plants were pre-treated (watering the soil until saturation) with $50 \%$ HoFs or mock, and $24 \mathrm{hpt}$ leaves were infected with Botrytis cinerea and evaluated at 72 hpi.

\section{RNA Extraction}

Arabidopsis thaliana leaves from 5 plants were harvested $24 \mathrm{hpt}$, pooled and immediately frozen in liquid nitrogen and kept at $-80^{\circ} \mathrm{C}$ until use. Total RNA was extracted using the Spectrum ${ }^{\mathrm{TM}}$ Plant total RNA Kit (www.sigmaaldrich.com) as described in the manufacturer's protocols. The integrity of extracted RNA was measured by agarose gel electrophoresis (1.2\%), concentrations and purity were determined by NanoDrop 2000/2000c (Thermo Fisher Scientific). Samples used for RNA-seq were also analyzed using an Agilent 2100 Bioanalyzer (Agilent Genomics).

\section{Genome-Wide Transcriptomic Analysis}

The RNA-seq libraries were prepared from isolated total RNA from 5 plants, pooled from three independent experiments, using the Illumina TruSeq RNA Sample Preparation Kit (Illumina, San Diego, CA, USA) following the manufacturer's instructions. The libraries were sequenced using an Illumina GAIIx platform for 72 paired-end cycles following the manufacturer's protocol. Sequences are publicly available through the Gene Expression Omnibus database under the accession number GSE113810 (https://www.ncbi.nlm.nih.gov/geo/query/acc.cgi? acc=gse113810). Contamination and adapter removal was carried out using in-house Perl scripts. Fastq sequences were filtered based on quality (FASTQ Quality Filter v0.0.6, Q 33, http://hannonlab.cshl.edu/fastx_toolkit/index.html) and mapped on Arabidopsis thaliana transcriptome (TAIR10) using Bowtie2 (Langmead and Salzberg, 2012). Gene expression was calculated using RSEM v1.3 (Li and Dewey, 2011) and compared between the two RNA-seq libraries using DEGseq v3.6 (Wang et al., 2010), and the FPKM data from RSEM. Only transcripts with a Log2 fold change $<-1$ or $>1$ with a $p$-value $<0.05$ were considered. DEGs identified in by genome-wide transcriptomic analysis were analyzed and classified into gene ontology classes (GO) using the analysis toolkit agriGO (http://bioinfo.cau.edu. $\mathrm{cn} /$ agriGO/) previously described (Du et al., 2010). Identification of commonly regulated DEGs from previously published data and from the present work were performed using the software FiRe ver. 2.2 as previously described (Garcion and Metraux, 2006).

\section{Real Time RT-PCR}

Pooled total RNA $(1.0 \mu \mathrm{g})$ from 5 plants, from two independent experiments, was retro-transcribed into cDNA according to the manufacturer's indications using the SCRIPT cDNA Synthesis Kit (Jena Bioscience www.jenabioscience.com). RT-qPCR was performed in 96-well plates with the Applied Biosystems StepOne $^{\mathrm{TM}}$ and StepOnePlus ${ }^{\mathrm{TM}}$ Real-Time PCR System (ThermoFisher Scientific), using SYBR Green Maxima SYBR Green/ROX qPCR Master Mix (2X) (ThermoFisher Scientific, 
www.thermofisher.com). Two independent experiments were analyzed with three technical replicates each. RT-qPCR conditions were as follows: an initial $95^{\circ} \mathrm{C}$ denaturation step for $15 \mathrm{~min}$ followed by denaturation for $15 \mathrm{~s}$ at $95^{\circ} \mathrm{C}$, annealing for $30 \mathrm{~s}$ at $60^{\circ} \mathrm{C}$, and extension for $30 \mathrm{~s}$ at $72^{\circ} \mathrm{C}$ for 45 cycles. Gene expression values were normalized using the mean expression of two genes: AT4G26410 and AT1G72150 previously described as stable reference genes (Serrano and Guzmán, 2004; Czechowski et al., 2005). Normalized gene expression was determined using the comparative $2^{-\Delta \Delta C T}$ method previously described (Schmittgen and Livak, 2008). Primers for ACS6, PR4, and PDF1.2 gene expression were previously described (Hael-Conrad et al., 2015).

\section{RESULTS}

\section{Compounds Released by Hanseniaspora opuntiae Protect Against the Plant Pathogen Corynespora cassiicola}

Yeasts have been characterized as biocontrol agents (BCAs) and eco-friendly alternatives to commercial pesticides against different plant pathogens (Liu et al., 2013); in particular, the antimicrobial compounds released, known as antifungal killer toxins or "mycocins" (Hatoum et al., 2012). In order to identify potential BCAs, a collection of yeast resident on Theobroma cacao fruits was isolated and the antimicrobial compounds released were tested against the fungal plant pathogen Corynespora cassiicola (Ferreira-Saab, 2018). One of the potential BCAs identified was Hanseniaspora opuntiae, which has been previously identified as part of the microbiome present in the cocoa bean fermentation process (Papalexandratou et al., 2013). In order to study the potential of Hanseniaspora opuntiae as biocontrol agent, Corynespora cassiicola spores were germinated on PDA media supplemented with $20 \%$ of compounds released by this yeast, identified as HoFs. In-vitro mycelia growth was inhibited by approximately $50 \%$, compared to the PDA control media (Figure 1A). Corynespora cassiicola has been described as an important pathogen of many crop plants, including soybean (Glycine max). Then we determined if HoFs extended their biocontrol effect on this crop. Soybean plants were treated with $20 \% \mathrm{HoFs}$ and after $24 \mathrm{hpt}$, infected with Corynespora cassiicola and at 120 hpi disease severity was quantified as previously described (Soares et al., 2009). A reduction of approximately $75 \%$ in disease severity, compared to the mock-treated control plants, was induced by HoFs $120 \mathrm{hpi}$ (Figure 1B). These results indicated that HoFs not only inhibited Corynespora cassiicola growth in-vitro, but can be also used as BCAs on soybean plants.

\section{The Pathosystem Arabidopsis thaliana-Botrytis cinerea Can be Used as a Model to Analyze the HoFs-Induced Defense Mechanisms}

In the field, application of BCAs has shown an inconsistent efficacy compared with synthetic chemical compounds and one possibility, to avoid this problem, is to better understand the
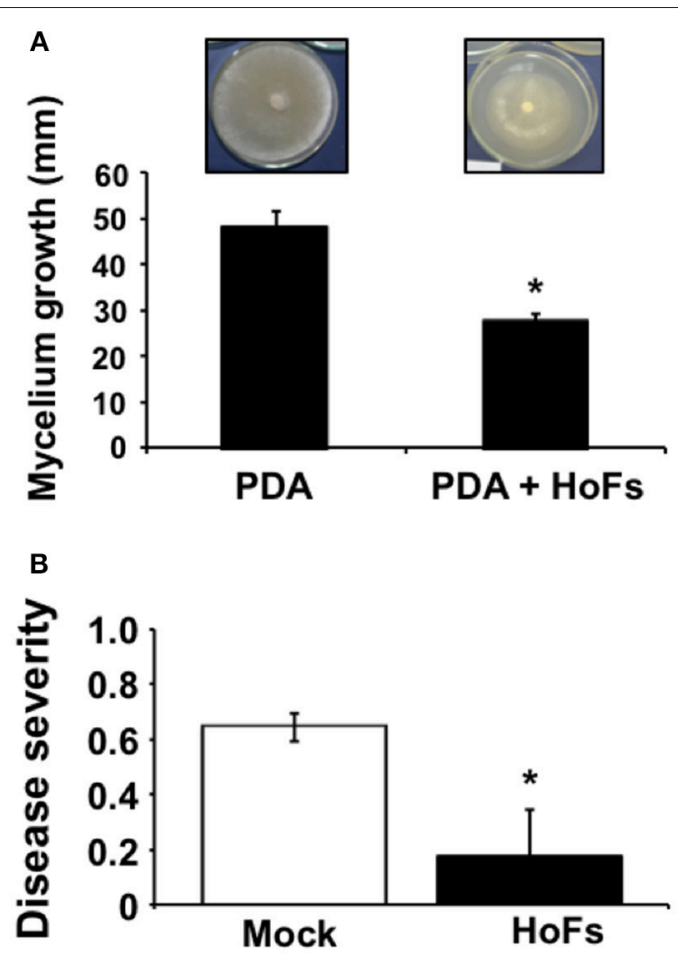

FIGURE 1 | HoFs inhibit Corynespora cassiicola growth in vitro and protect Glycine max plants against this pathogen. (A) Spore suspension of Corynespora cassiicola $\left(3 \times 10^{5}\right.$ spores $\left.\mathrm{ml}^{-1}\right)$ was placed on the center of the Petri dish containing PDA (Mock) or PDA supplemented with $20 \% \mathrm{HoFs}$ and incubated at $22^{\circ} \mathrm{C}$ for $72 \mathrm{~h}$. Growth inhibition was evaluated measuring the diameter of the mycelium on the dish. Representative pictures of the inhibitory assay are included above each histogram as a visual illustration. (B) Soybean plants were grown until the V4 developmental stage; afterwards, sprayed until saturation with distilled sterile water (Mock) or $20 \%$ HoFs every 7 days, for 4 weeks. $24 \mathrm{~h}$ after the last treatment, plants were infected with Corynespora cassiicola spore suspension $\left(3 \times 10^{5}\right.$ spores $\left.\mathrm{ml}^{-1}\right)$ and disease severity was determined 120 hpi, as previously described (Soares et al., 2009). Bars represent mean values ( $\pm S D$ ) of three independent experiments. Asterisks indicate a statistically significant difference between Mock- and HoFs-treated samples, according to the Student's $T$-test $(P \leq 0.05)$.

molecular mechanisms behind the application of BCAs (Massart et al., 2015). In order to characterize the molecular mechanisms underlying the HoFs-induced biocontrol effect, we used the wellcharacterized plant-pathosystem Arabidopsis thaliana-Botrytis cinerea. First, we determined if HoFs inhibited the development of the necrotroph pathogen under in-vitro conditions (Figure 2). Analyzing a dose-dependent response, we observed that Botrytis cinerea grown on PDA media supplemented with 20 and $30 \%$ HoFs, showed about $25 \%$ inhibition of mycelial growth (Figure 2A). Increasing HoFs concentration up to 40 and 50\%, directly correlated with a higher reduction of mycelial growth (between 70 and $80 \%$ inhibition, respectively), showing a dosedependent response induced by HoFs (Figure 2A). To determine if HoFs directly affect the germination and the production of Botrytis cinerea spores, we analyzed the development of the fungus in the presence of $20 \%$ HoFs (Figures 2B,C). We determined that spores can germinate at $20 \%$ HoFs, but hyphae 
growth was inhibited (Figure 2B). Additionally, we observed that mycelia developed under this conditions did not further produce spores (Figure 2C). These results suggest that HoFs have antifungal effect on Botrytis cinerea. Next, 4-week-old

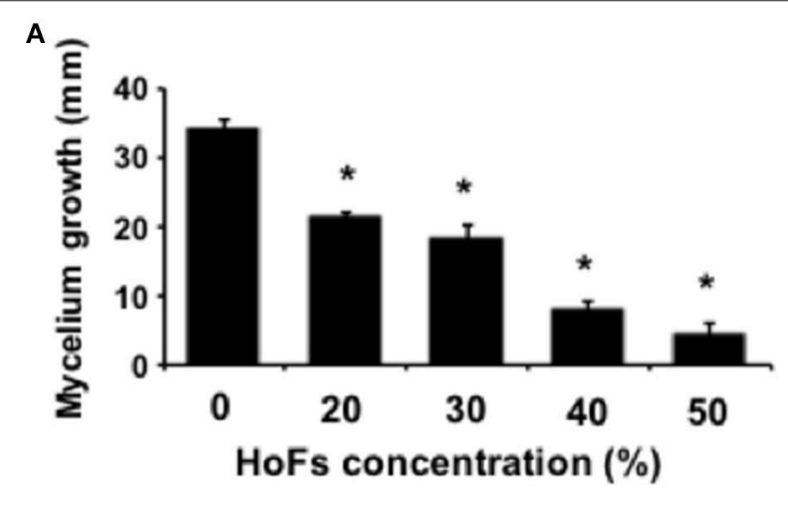

-

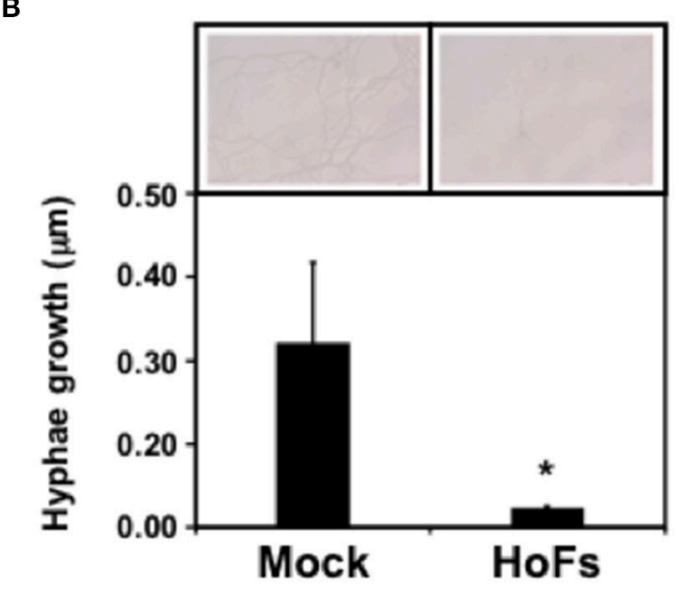

C

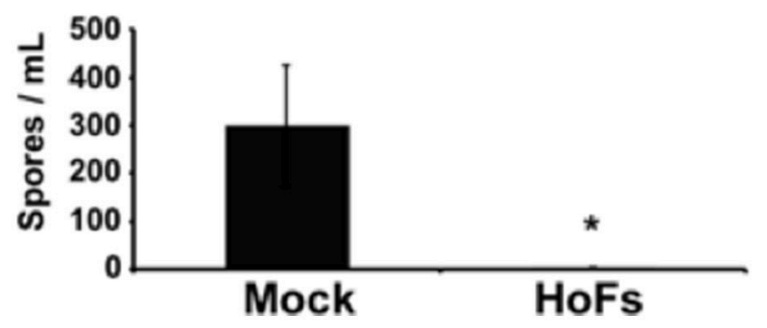

FIGURE 2 | HoFs induced a Botrytis cinerea development inhibition. (A) Spore suspension of Botrytis cinerea $\left(5 \times 10^{4}\right.$ spores $\left.\mathrm{ml}^{-1}\right)$ was placed on the center of the Petri dish containing PDA supplemented with indicated concentrations of $\mathrm{HoFs}$ and incubated at $22^{\circ} \mathrm{C}$. Growth inhibition was evaluated measuring the diameter of the mycelium on the dish $72 \mathrm{hpi}$. (B) Hyphae elongation produced by Botrytis cinerea, grown on 20\% HoFs 24 hpi, was quantified as previously described (Hael-Conrad et al., 2015). A representative image of each treatment is presented. (C) Spores produced by Botrytis cinerea 15 days after the grown on $20 \% \mathrm{HoFs}$, were isolated and quantified as previously described (L'Haridon et al., 2011). Bars represent mean values $( \pm S D$ ) of three independent experiments. Asterisks indicate a statistically significant difference between $0 \%$ and the indicated concentrations of HoFs, according to the Student's $T$-test $(P \leq 0.05)$.
Arabidopsis thaliana plants were pre-treated with 50\% HoFs $24 \mathrm{hpt}$ and then infected with Botrytis cinerea. We observed a strong inhibition of the lesion caused by this pathogen on HoFs-treated plants compared to mock-treated samples, 72 hpi (Figure 3A). Additionally, a similar dose-dependent effect, observed under in-vitro conditions (Figure 2A), was determined in planta, since at higher HoFs concentration a smaller lesion size was quantified (Figure 3B). Then, to evaluate for how long HoFs can protect Arabidopsis thaliana plants against Botrytis cinerea, different hpt were assayed, measuring the lesion size at $72 \mathrm{hpi}$. For all of the times analyzed (24 to $120 \mathrm{hpt}$ ), HoFs-treated plants showed significant differences compared to mock-treated control samples (Figure 4), indicating that HoFs induced a protective effect over the plant-pathogen interaction at all of these time points. Taken together, these results indicated that HoFs protect Arabidopsis thaliana against Botrytis cinerea and that this pathosystem can be used as a model to characterize the molecular changes induced by HoFs application.

\section{HoFs Induced a Systemic Protection Against Botrytis cinerea}

Under in-vitro conditions we observed an antifungal effect on Botrytis cinerea growth (Figure 2), this observation rises the

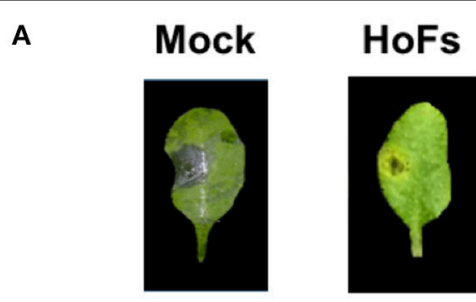

B

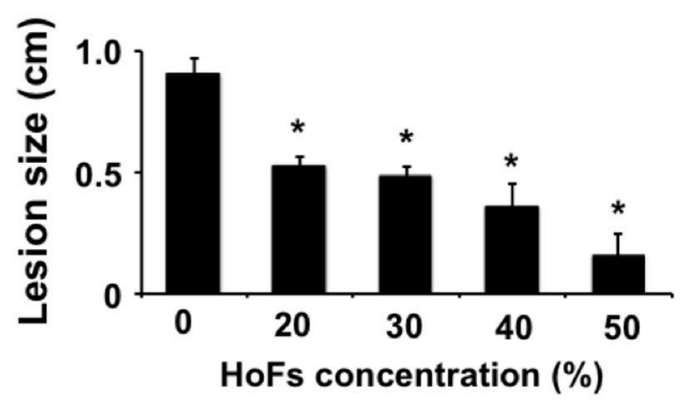

FIGURE 3 | HoFs protect Arabidopsis thaliana plants against Botrytis cinerea. (A) 4-week-old Arabidopsis thaliana plants were sprayed until saturation with YNB medium (Mock) or $50 \%$ HoFs. Twenty-Four hpt $3 \mu$ l droplets containing a Botrytis cinerea spore suspension $\left(5 \times 10^{4}\right.$ spores $\left.\mathrm{ml}^{-1}\right)$ were applied and infection symptoms were evaluated $72 \mathrm{hpi}$. Representative pictures of the inhibitory assay are included as a visual illustration. (B) Four-week-old Arabidopsis thaliana plants were treated with the indicated HoFs concentration and infected as indicated above. Infection symptoms were evaluated 72 hpi by measuring lesion size $(\mathrm{cm})$. Bars represent mean values $( \pm S D)$ of three independent experiments each with twenty replicates. Asterisks indicate a statistically significant difference between Mock- and HoFs-treated samples, according to the Student's $T$-test $(P \leq 0.05)$. 


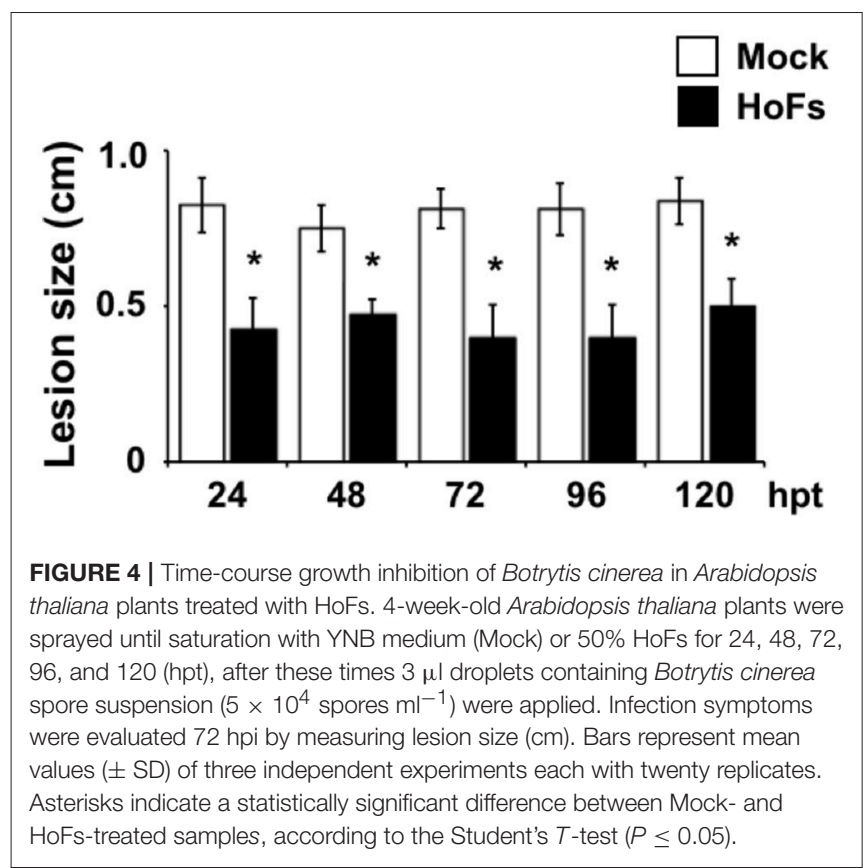

questions of whether the protective effect observed in planta was induced by the direct effect of HoFs localized on the local leaf surface or by the modification of the plant defense responses itself. In order to clarify this question, we applied HoFs directly to the roots and we infected the untreated leaves (systemic) with Botrytis cinerea. 72 hpi HoFs-root-treated plants showed a similar significant reduction of lesion size, as the local HoFstreated leaves (Figure 5). These results suggest two possibilities: (1) HoFs can be transported from the roots to the the entire plant, inhibiting Botrytis cinerea due to their antifungal effect and (2) HoFs might play a role as a potential elicitor of the defense responses that leads to a systemic resistance against the necrotrophic pathogen Botrytis cinerea. Either way, these result indicated that application of HoFs can triggered a systemic protection against this pathogen.

\section{HoFs Induced a Reprograming of the Arabidopsis thaliana Transcriptome}

During the last decade large-scale transcriptomic analysis have been used to understand how BCAs improve plant health (Massart et al., 2015). However, to our knowledge, only few a studies have used Arabidopsis thaliana as a model (Feng et al., 2012; Morán-Diez et al., 2012). In order to discover the transcriptional modifications induced by HoFs, the transcriptome of HoFs-treated plants was analyzed by RNAseq (Supplementary Table 1, Figure 6). The expression of 186 and 46 genes was down- or up-regulated, respectively in HoFstreated plants compared to non-induced samples (Figure 6A). GO analysis revealed that the most significant differentially expressed genes (DEGs), induced and repressed belonged to response to stress, chemical and abiotic stimulus, among others (Table 1).

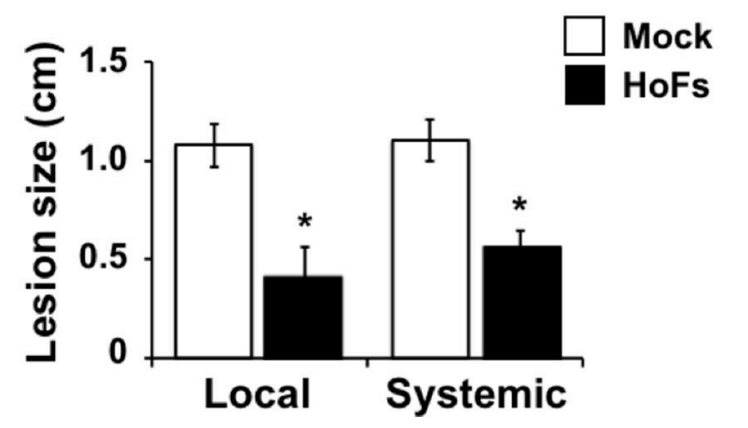

FIGURE 5 | Systemic effect induced by HoFs against Botrytis cinerea in Arabidopsis thaliana plants. 4 week-old Arabidopsis thaliana plants were pre-treated in the roots (watered soil until saturation) with YNB medium (Mock) or $50 \% \mathrm{HoFs}$ and $24 \mathrm{hpt} \mathrm{leaves} \mathrm{infected} \mathrm{with} \mathrm{Botrytis} \mathrm{cinerea} \mathrm{and} \mathrm{evaluated} \mathrm{at}$ $72 \mathrm{hpi}$. Bars represent mean values ( $\pm \mathrm{SD}$ ) of three independent experiments each with twenty replicates. Asterisks indicate a statistically significant difference between Mock- and HoFs-treated samples, according to the Student's $T$-test $(P \leq 0.05)$.

GO analysis revealed that induced DEGs belonged to a group responsive to chitin, defense response, response to fungus and jasmonic acid (JA) biosynthetic processes (Table 1B). Previous reports have shown that Arabidopsis thaliana defense responses to Botrytis cinerea are JA- and ET-dependent (Thomma et al., 2001; Ferrari et al., 2003; Glazebrook, 2005). In order to validate the transcriptomic analysis, we compared the expression of JA- and ET-related genes, that were induced by HoFs (Figure 6B). Gene expression of the enzyme catalyzing the first and rate-limiting step of ET biosynthesis, 1-aminocyclopropane1-carboxylate synthase 6 (ACS6), the ET-responsive gene PATHOGENESIS-RELATED 4 (PR4) and ET- and JA-responsive plant defensin gene (PDF1.2) were measured (Figure 6B). ACS6, PR4 and PDF1.2 have been previously described to be expressed during Botrytis cinerea infection (Windram et al., 2012; HaelConrad et al., 2015) and in agreement with these observations, we detected an up-regulation of these genes in HoFs-treated plants, compared to mock-treated samples (Figure 6B). These results help us to validate our genome-wide analysis and indicated that resistance to Botrytis cinerea induced by HoFs application, can be mediated, at least partially, by the transcriptional reprograming of the plant defense responses, in particular JA- and ET-induced pathway. This valuable information (Supplementary Table 1) can be used to uncover the HoFs-induced defense responses.

\section{Transcriptional Reprograming Induced by HoFs Is Different Than Other BCAs Previously Reported}

Two genome-wide transcriptomic analysis have been performed to characterize the mode of action of BCAs using Arabidopsis thaliana as a model. The first, analyzed the transcriptome changes induced by the pre-inoculation ( $24 \mathrm{hpi}$ ) of Arabidopsis thaliana plants with Ralstonia solanacearum $\Delta$ hrpB mutant strain, which has been previously shown to protect against the virulent strain of this phytopathogenic root bacteria on tomato (Frey et al., 
A

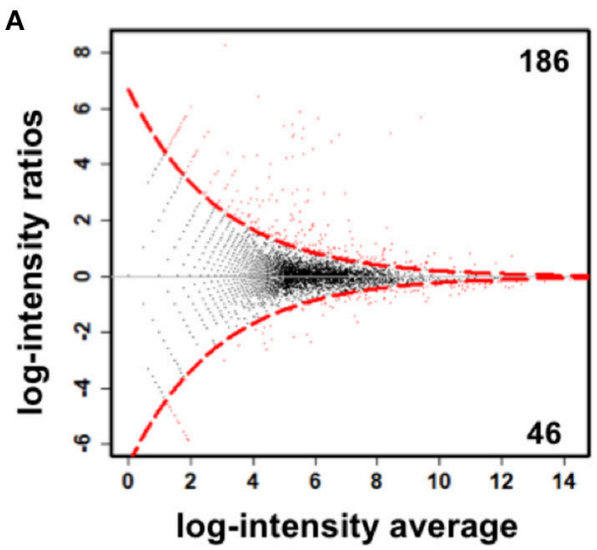

B
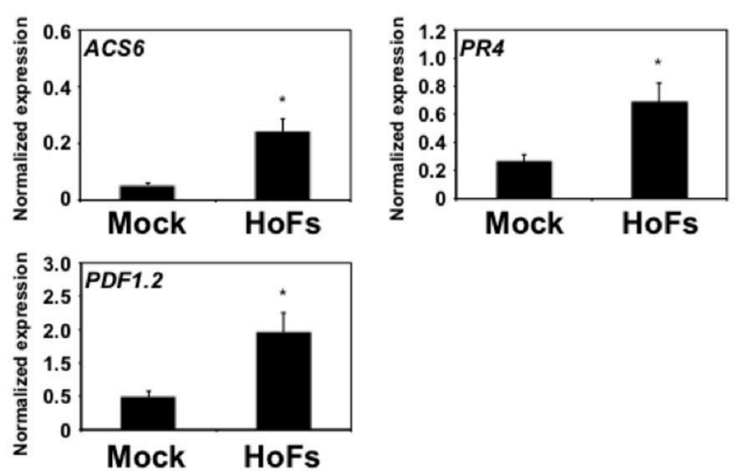

FIGURE 6 | Genome-wide transcriptomic analysis of HoFs-induced Arabidopsis thaliana plants. Five Arabidopsis thaliana 4-week-old plants, were sprayed until saturation with YNB medium (Mock) or 50\% HoFs and total RNA, from three independent experiments, were pooled and sequenced (RNA-seq). (A) MA-plot of Mock- vs. HoFs-treated samples. The red points are the genes identified as differentially expressed ( $p$-value $<0.05$ ). Black dots represent genes with similar expression. The discontinued red line represents the limit between similarly and differentially expressed genes. The black horizontal line at zero provides a visual check for symmetry. (B) Quantitative real-time PCR (RT-qPCR) analysis of JA- and ET-induced genes. Expression of ACS6, PR4 and PDF1.2 was determined and normalized with respect to the mean of two reference genes AT4G26410 and AT1G72150, as previously described (Serrano and Guzmán, 2004; Hael-Conrad et al., 2015). The value in each histogram is the mean ( \pm SE) of two independent experiments $(n=10)$ with three technical replicates for each RT-qPCR assay. Asterisks indicate a statistically significant differences between Mock- and HoFs-treated samples, according to Student's $T$-test $(p<0.05)$.

1994). From this analysis 152 and 336 genes were identified to be down- and up-regulated, respectively (Feng et al., 2012). Interestingly, $26 \%$ of the up-regulated genes were related to biosynthesis of abscisic acid (ABA) and signaling, suggesting an important role of this plant hormone on the defense mechanisms induced by this BCA (Feng et al., 2012). The other, described the transcriptomic response of Arabidopsis thaliana plants after inoculation with the biocontrol fungus Trichoderma harzianum at 24 hpi (Morán-Diez et al., 2012). From this analysis, only 66 DEGs were identified, 33 up- and 33 down-regulated as a result of the interaction (Morán-Diez et al., 2012). The expression of SA- and JA-related genes was down regulated, while genes involved in the abiotic stresses were induced (MoránDiez et al., 2012). Here, in order to identify if treatments with BCAs share a similar transcriptomic signature, we analyzed the commonly co-expressed DEGs in Arabidopsis thaliana plants treated for 24 hpi with Ralstonia solanacearum $\Delta \mathrm{hrpB}$ mutant strain, $24 \mathrm{hpi}$ with Trichoderma harzianum and $24 \mathrm{hpt}$ with HoFs (Figure 7). Only 2 and 7 genes were down- and upregulated, respectively, after the pre-inoculation with $\Delta \mathrm{hrpB}$ mutant and infection with Trichoderma harzianum (Figure 7), indicating that the two biocontrols triggered different defense response pathways. However, is worth to mentioning that we determined that DEGs induced or repressed by HoFs are not part of the same core of genes regulated by these other BCAs (Figure 7). These results indicate that HoFs-induced DEGs have not been previously identified as part of BCAs-induced defense mechanisms.

\section{DISCUSSION}

\section{HoFs Have the Potential to Protect Against the Broad Host-Range Necrotrophic Fungi Corynespora cassiicola and Botrytis cinerea}

The necrotrophic fungi Corynespora cassiicola and Botrytis cinerea are considered as important plant pathogens that affect pre- and post-harvest processes. Corynespora cassiicola resides on plant surfaces, nematodes cysts and human skin and can infect at least 530 plant species, including several important crops such as cowpea, cucumber, papaya, rubber, soybean and tomato (Dixon et al., 2009). While Botrytis cinerea, is a broad host-range necrotrophic fungus, commonly known as gray mold, that can infect more than 200 plant species, and for this, it has been classified as the second most important phytopathogen (Dean et al., 2012). Several elicitors have been previously described to protect the plants against Botrytis cinerea, including rhamnolipids, oligogalacturonides, chitosan, ceratoplatanin and the proteins PebC1 and AsES (Trotel-Aziz et al., 2006; Ferrari et al., 2007; Sanchez et al., 2012; Baccelli et al., 2014; Zhang et al., 2014; Feng et al., 2015; HaelConrad et al., 2015). However, to our knowledge, there is only one report where biocontrol agents were analyzed for their effect against Corynespora cassiicola under in-vitro and in field conditions. This early study, included the microorganisms Trichoderma spp., Bacillus subtilis, and Pseudomonas florescence and the elicitors from garlic bulb and neem seed kernel extracts (Manju et al., 2014). In our work, we determined that the elicitors released by the biocontrol yeast Hanseniaspora opuntiae (HoFs) can protect Glycine max and Arabidopsis thaliana plants against the necrotroph pathogens Corynespora cassiicola and Botrytis cinerea, respectively. Under in-vitro and in-planta conditions, HoFs show a dose-dependent behavior, similar to other elicitors previously characterized (TrotelAziz et al., 2006; Hael-Conrad et al., 2015). Additionally, we determined that the HoFs-induced protective effect on Arabidopsis thaliana plants against Botrytis cinerea, can be induced after $24 \mathrm{~h}$ pretreatment and maintained without 
TABLE 1 | Gene ontology (GO) enrichment analysis of differentially expressed genes of HoFs-treated Arabidopsis thaliana plants.

GO ID Description $\begin{gathered}\text { No. } \\ \text { Genes }\end{gathered}$

\begin{tabular}{|c|c|c|c|}
\hline \multicolumn{4}{|l|}{ (A) } \\
\hline GO:0009628 & Response to abiotic stimulus & 9 & 5.90E-06 \\
\hline GO:0050896 & Response to stimulus & 14 & 7.10E-06 \\
\hline GO:0006950 & Response to stress & 11 & 5.00E-06 \\
\hline GO:0042221 & Response to chemical stimulus & 10 & 1.40E-05 \\
\hline GO:0006810 & Transport & 7 & 1.30E-03 \\
\hline GO:0051234 & Establishment of localization & 7 & 1.40E-03 \\
\hline GO:0051179 & Localization & 7 & 1.70E-03 \\
\hline GO:0009725 & Response to hormone stimulus & 5 & 2.00E-03 \\
\hline GO:0009719 & Response to endogenous stimulus & 5 & 2.90E-03 \\
\hline GO:0010033 & Response to organic substance & 5 & 7.60E-03 \\
\hline GO:0022891 & $\begin{array}{l}\text { Substrate-specific transmembrane } \\
\text { transporter activity }\end{array}$ & 5 & 1.40E-03 \\
\hline GO:0022892 & Substrate-specific transporter activity & 5 & 2.80E-03 \\
\hline GO:0022857 & Transmembrane transporter activity & 5 & 3.70E-03 \\
\hline GO:0005215 & Transporter activity & 5 & 1.10E-02 \\
\hline \multicolumn{4}{|l|}{ (B) } \\
\hline GO:0006950 & Response to stress & 51 & 1.10E-23 \\
\hline GO:0050896 & Response to stimulus & 61 & $2.50 \mathrm{E}-20$ \\
\hline GO:0015979 & Photosynthesis & 16 & $3.80 \mathrm{E}-17$ \\
\hline GO:0042221 & Response to chemical stimulus & 41 & $3.60 \mathrm{E}-17$ \\
\hline GO:0006091 & $\begin{array}{l}\text { Generation of precursor metabolites } \\
\text { and energy }\end{array}$ & 18 & $5.90 \mathrm{E}-16$ \\
\hline GO:0009611 & Response to wounding & 14 & $2.60 \mathrm{E}-13$ \\
\hline GO:0010033 & Response to organic substance & 29 & 3.30E-13 \\
\hline GO:0009605 & Response to external stimulus & 18 & 4.70E-13 \\
\hline GO:0044237 & Cellular metabolic process & 77 & 5.90E-13 \\
\hline GO:0019684 & Photosynthesis, light reaction & 11 & $1.70 \mathrm{E}-12$ \\
\hline GO:0010200 & Response to chitin & 12 & $4.00 \mathrm{E}-12$ \\
\hline GO:0009987 & Cellular process & 89 & $9.70 \mathrm{E}-12$ \\
\hline GO:0008152 & Metabolic process & 83 & 2.80E-11 \\
\hline GO:0009409 & Response to cold & 14 & $1.70 \mathrm{E}-10$ \\
\hline GO:0009743 & Response to carbohydrate stimulus & 12 & 6.40E-10 \\
\hline GO:0009607 & Response to biotic stimulus & 17 & 1.90E-09 \\
\hline GO:0009266 & Response to temperature stimulus & 15 & 2.60E-09 \\
\hline GO:0044249 & Cellular biosynthetic process & 48 & 5.60E-09 \\
\hline GO:0031408 & Oxylipin biosynthetic process & 6 & 1.00E-08 \\
\hline GO:0009628 & Response to abiotic stimulus & 24 & 1.10E-08 \\
\hline GO:0009145 & $\begin{array}{l}\text { Purine nucleoside triphosphate } \\
\text { biosynthetic process }\end{array}$ & 7 & 1.50E-08 \\
\hline GO:0009142 & $\begin{array}{l}\text { Nucleoside triphosphate biosynthetic } \\
\text { process }\end{array}$ & 7 & 1.60E-08 \\
\hline GO:0009144 & $\begin{array}{l}\text { Purine nucleoside triphosphate } \\
\text { metabolic process }\end{array}$ & 7 & 1.60E-08 \\
\hline GO:0009141 & $\begin{array}{l}\text { Nucleoside triphosphate metabolic } \\
\text { process }\end{array}$ & 7 & 2.00E-08 \\
\hline GO:0009058 & Biosynthetic process & 48 & $1.90 \mathrm{E}-08$ \\
\hline GO:0031407 & Oxylipin metabolic process & 6 & 3.00E-08 \\
\hline GO:0009620 & Response to fungus & 9 & 3.30E-08 \\
\hline GO:0051707 & Response to other organism & 15 & $3.90 \mathrm{E}-08$ \\
\hline
\end{tabular}

(Continued)
TABLE 1 | Continued

\begin{tabular}{llcl}
\hline GO ID & Description & $\begin{array}{c}\text { No. } \\
\text { Genes }\end{array}$ & p-Value \\
\hline GO:0009414 & Response to water deprivation & 10 & $6.00 \mathrm{E}-08$ \\
GO:0009150 & $\begin{array}{l}\text { Purine ribonucleotide metabolic } \\
\text { process }\end{array}$ & 7 & $7.40 \mathrm{E}-08$ \\
GO:0009415 & Response to water & 10 & $9.20 \mathrm{E}-08$ \\
GO:0006164 & Purine nucleotide biosynthetic & 7 & $1.60 \mathrm{E}-07$ \\
& process & 16 & $1.50 \mathrm{E}-07$ \\
GO:0006952 & Defense response & 7 & $1.80 \mathrm{E}-07$ \\
GO:0006163 & Purine nucleotide metabolic process & 12 & $1.80 \mathrm{E}-07$ \\
GO:0006970 & Response to osmotic stress & 7 & $2.40 \mathrm{E}-07$ \\
GO:0009259 & Ribonucleotide metabolic process & 5 & $2.70 \mathrm{E}-07$ \\
GO:0009695 & Jasmonic acid biosynthetic process & 6 & $2.90 \mathrm{E}-07$ \\
GO:0015992 & Proton transport & 6 & $2.90 \mathrm{E}-07$ \\
GO:0006818 & Hydrogen transport & &
\end{tabular}

Biological process identified to be (A) down-regulated and (B) up-regulated on HoFstreated compared to Mock-treated samples.

significant reduction for up to 5 days (Figure 4). Taken together, these results indicated that HoFs have the potential to be used as biocontrols against these agronomically important pathogens. Furthermore, it will be interesting to study if HoFs can protect against other pathogens, including other fungi, bacteria and/or herbivores.

\section{HoFs Induce Local and Systemic Protection Against Botrytis cinerea}

HoFs show a protective effect in-planta, but additionally, they also inhibited the development of the pathogens under in-vitro conditions (Figures 1, 2). These results suggest that HoFs might work as fungicides, however, since we also observed a systemic protection in Arabidopsis thaliana plants (Figure 5), we can not discard the idea that HoFs can either be diffused through the whole plant and/or that, once inside the plant cell, they can induce the defense responses as true elicitors. The possibility that HoFs might act as elicitors inducing the defense responses is supported by the changes in the genome-wide transcriptomic machinery, since genes of the JA- and ET-related pathways that have been previously reported to be involved in the Botrytis cinerea response, are induced (Figure 6). Interestingly, a similar in-vitro inhibitory effect on Botrytis cinerea and the induction of the defense responses have been observed with other wellcharacterized elicitor, the chitosan (Trotel-Aziz et al., 2006). Exogenous application of elicitors has diverse and, sometimes, contradictory effect. While chitosan has been described to improve plant growth (Yin et al., 2016), constitutive activation of the defense responses by oligogalacturonides (OGs), have been recently shown to affect the plant growth rate, suggesting a defense-growth trade-off (Benedetti et al., 2018). Now, the question if HoFs have a similar effect is still open. Either way, the local and systemic protection induced by HoFs, might facilitate their application and might give them the potential to be used on the field to protect the crops against these pathogens. 
A

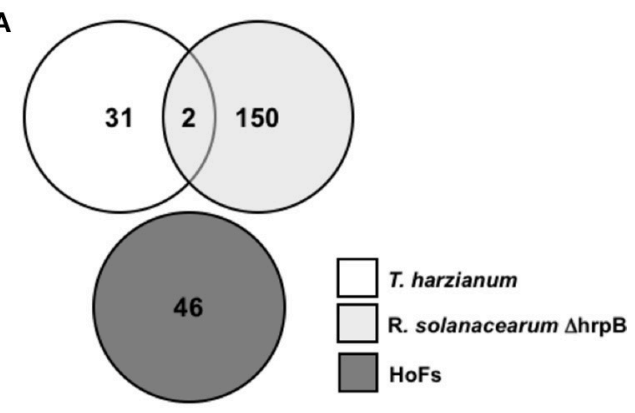

B

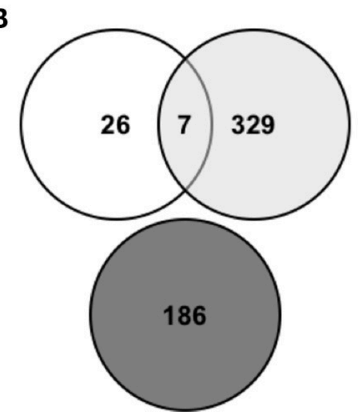

FIGURE 7 | HoFs-induced differentially expressed genes (DEGs) have not been previously identified as part of BCAs-induced defense mechanisms. (A) and (B) Venn diagrams representing overlapping or non-overlapping gene sets of differentially down- and up-regulated genes respectively, previously identified in Arabidopsis thaliana plants induced for $24 \mathrm{hpi}$ with Trichoderma harzianum (Morán-Diez et al., 2012), Ralstonia solanacearum $\Delta$ hrpB mutant strain (Feng et al., 2012) or HoFs, as indicated.

\section{HoFs Might Induce Systemic Protection Against Botrytis cinerea by Triggering JA- and ET-Dependent Signaling Pathways, but Not SA-Induced Pathway}

In order to regulate the complex interactions with the microorganisms, plants have developed inducible defense responses. The first line of defense, that is induced by the recognition of molecules, including the elicitors, is called plant innate immunity (Boller and Felix, 2009). Once the immunity is induced, the response is amplified by the induction of SA-, JA-, and ET-induced signaling pathways (Garcion et al., 2007; Dangl et al., 2013). These defense mechanisms work coordinately to regulate the plant-pathogen interactions, locally and systemically by priming the defense responses, including the systemic and induced acquired resistance (SAR and IAR) (Craig et al., 2009; Tsuda and Somssich, 2015). Here we proposed the possibility that HoFs might work as elicitor to induce a systemic protection against Botrytis cinerea (Figure 5). JA- and ET-related genes are induced after HoFs application (Figure 6, Table 1), but the SAinduced gene PR1 is actually repressed (Supplementary Table 1). For decades, SA has been proposed to govern the induction of SAR, however, multiple reports have revealed that systemic defense responses are not regulated and induced only by SA but by an intricate and complex network that involves other phytohormones including JA and ET (reviewed by Conrath et al., 2015; Klessig et al., 2018). With this in mind, characterization of HoFs-induced defense responses warrants further studies.

\section{Exploring the Pathosystem Arabidopsis thaliana-Botrytis cinerea to Characterize HoFs-Induced Defense Mechanisms}

Elicitors have the potential to be used in agriculture as an alternative to chemical fungicides, however, in order to optimize their application and activity on the field, it is necessary to know and characterize their mode of action (Wiesel et al., 2014). In this report, we used the well characterized pathosystem Botrytis cinerea-Arabidopsis thaliana to identify the transcriptomic changes induced by HoFs (Figure 6, Table 1, Supplementary Table 1). Using genetic, molecular and omics tools applied on different plant models, including Arabidopsis thaliana, plant-microbe and microbe-microbe interactions, have been characterized at the molecular level (Kroll et al., 2017). In the plants, this characterization includes, the analysis of the early events during the beneficial and pathogenic interactions (Zipfel and Oldroyd, 2017), the transcriptional regulation of plant defense responses (Birkenbihl et al., 2017) and the elicitormediated activation of plant immunity (Cheng et al., 2018). On the other hand, the molecular analysis of the pathogens Corynespora cassiicola and Botrytis cinerea also has also been improved with the identification of the genomic sequence and the transcriptomic characterization during the interaction with the plants (Windram et al., 2012; Shrestha et al., 2017; Van Kan et al., 2017). Now, with all this available information and with the HoFs-induced DEGs identified from our work, further studies are warranted, that might help us to understand the molecular defense mechanisms induced by HoFs.

\section{Triggered Transcriptional Modulation of Plant Defense Responses Is Broadly BCAs-Specific}

Only two BCAs have been characterized by analyzing genomewide transcriptional changes in Arabidopsis thaliana, using the bacterium Ralstonia solanacearum $\Delta \mathrm{hrpB}$ mutant strain and the fungus Trichoderma harzianum (Feng et al., 2012; Morán-Diez et al., 2012). In order to identify similarities between the transcriptome induced by different-origin BCAs, we compared the DEGs from these two reports and those induced by yeast-derived HoFs (Figure 7). Remarkably, we observed that only 9 DEGs are shared in response to Trichoderma harzianum and Ralstonia solanacearum treatments and that there were no similarities with HoFs treatment (Figure 7). In agreement with these observations, it was previously reported that the expression of JA-related genes was down-regulated after Ralstonia solanacearum induction (Morán-Diez et al., 2012), while we determined that after HoFs treatment these genes were up-regulated (Figure 6B). Similar differential responses have been described in others plant-microbe interactions, for example, the pathogenic bacterium Pseudomonas syringae has been shown to induced the SA-induced signaling pathway (Grant and Jones, 2009; Verhage et al., 2010), while the fungus Botrytis 
cinerea induced JA- and ET-signaling pathways (Thomma et al., 2001; Glazebrook, 2005). To further highlight the complexity of these interactions, other reports have also shown contradictory results on the phytohormone-dependent responses induced by biotrophic and necrotrophic pathogens, since complex crosstalks and multifactorial dependence between SA-, JA-, and ET-signaling pathways have been described (Koornneef and Pieterse, 2008; Pieterse et al., 2009; Hael-Conrad et al., 2015). These observations suggest that both, the triggered defense mechanisms and the protective effect against a particular pathogen(s) are differentially regulated depending of the origin of BCAs.

Summarizing, HoFs induce local and systemic defense responses to broad host-range necrotrophic fungi. HoFs induce a transcriptional reprograming of Arabidopsis thaliana plants, and this genome-wide information can be used as starting point to understand the molecular basis of HoFs-triggered responses. Future work is now directed to characterize the biochemical nature of HoFs, including the chemical identity/identities of the elicitor(s).

\section{AUTHOR CONTRIBUTIONS}

DF, CS, AT, KS-E and MS conceived and designed the experiments. MF-S, MT, WA, EP, and DF performed the

\section{REFERENCES}

Baccelli, I., Lombardi, L., Luti, S., Bernardi, R., Picciarelli, P., Scala, A., et al. (2014). Cerato-platanin induces resistance in Arabidopsis leaves through stomatal perception, overexpression of salicylic acid- and ethylenesignalling genes and camalexin biosynthesis. PLoS ONE 9:e100959. doi: 10.1371/journal.pone.0100959

Barkai-Golan, R. (ed.). (2001). "Chapter 2-Postharvest Disease Initiation," in Postharvest Diseases of Fruits and Vegetables (Amsterdam: Elsevier), 3-24.

Benedetti, M., Verrascina, I., Pontiggia, D., Locci, F., Mattei, B., De Lorenzo, G., et al. (2018). Four Arabidopsis berberine bridge enzyme-like proteins are specific oxidases that inactivate the elicitor-active oligogalacturonides. Plant J. 94, 260-273. doi: 10.1111/tpj.13852

Bhadauria, V. (2016). OMICS in plant disease resistance. Curr. Issues Mol. Biol. 19, $1-2$.

Birkenbihl, R. P., Liu, S., and Somssich, I. E. (2017). Transcriptional events defining plant immune responses. Curr. Opin. Plant Biol. 38, 1-9. doi: 10.1016/j.pbi.2017.04.004

Boller, T., and Felix, G. (2009). A renaissance of elicitors: perception of microbe-associated molecular patterns and danger signals by pattern-recognition receptors. Annu. Rev. Plant Biol. 60, 379-406. doi: 10.1146/annurev.arplant.57.032905.105346

Cheng, C.-H., Shen, B.-N., Shang, Q.-W., Liu, L.-Y., Peng, K.-C., Chen, Y.-H., et al. (2018). Gene-to-gene network analysis of the mediation of plant innate immunity by the eliciting plant response-like 1 (Epl1) elicitor of Trichoderma formosa. Mol. Plant Microbe Interact. 31, 683-691 doi: 10.1094/MPMI-01-18-0002-TA

Cirvilleri, G., Bonaccorsi, A., Scuderi, G., and Scortichini, M. (2005). Potential biological control activity and genetic diversity of Pseudomonas syringae pv. syringae strains. J. Phytopathol. 153, 654-666. doi: 10.1111/j.1439-0434.2005.01033.x

Conrath, U., Beckers, G. J. M., Langenbach, C. J. G., and Jaskiewicz, M. R. (2015). Priming for enhanced defense. Annu. Rev. Phytopathol. 53, 97-119. doi: 10.1146/annurev-phyto-080614-120132 experiments. DF, CS, AT, and MS wrote and revised the paper. All authors approved the final version of the manuscript.

\section{ACKNOWLEDGMENTS}

We thank Antony Buchala for critical reading and comments of the manuscript. We thank the next-generation sequencing core facility of the Institute of Biotechnology-UNAM, for their technical support. MF-S and KS-E are supported by Conselho Nacional de Desenvolvimento Científico e Tecnológico $(\mathrm{CNPq})$ and Coordenação de Aperfeiçoamento de Pessoal de Nível Superior (Capes), Brazil. WA acknowledges a fellowship, No. 240087, from Consejo Nacional de Ciencia y Tecnología (CONACYT), México. This work was supported by funds from Dirección General de Asuntos del Personal Académico-UNAM, México grants PAPIIT IA203218, IA200816, IN208116, and IA200218 to DF, AT, CS, and MS, as well as the Ciencias Básicas grant from CONACYT No. 253494 and No. 237713 to AT and CS.

\section{SUPPLEMENTARY MATERIAL}

The Supplementary Material for this article can be found online at: https://www.frontiersin.org/articles/10.3389/fmicb. 2018.01596/full\#supplementary-material

Craig, A., Ewan, R., Mesmar, J., Gudipati, V., and Sadanandom, A. (2009). E3 ubiquitin ligases and plant innate immunity. J. Exp. Bot. 60, 1123-1132. doi: 10.1093/jxb/erp059

Czechowski, T., Stitt, M., Altmann, T., Udvardi, M. K., and Scheible, W. R. (2005). Genome-wide identification and testing of superior reference genes for transcript normalization in Arabidopsis. Plant Physiol. 139, 5-17. doi: 10.1104/pp.105.063743

Dangl, J. L., Horvath, D. M., and Staskawicz, B. J. (2013). Pivoting the plant immune system from dissection to deployment. Science 341, 746-751. doi: 10.1126/science.1236011

Dean, R., Van Kan, J. L., Pretorius, Z. A., Hammond-Kosack, K. E., Di Pietro, A., Foster, G. D., et al. (2012). The top 10 fungal pathogens in molecular plant pathology. Mol. Plant Pathol. 13, 414-430. doi: 10.1111/j.1364-3703.2011.00783.x

Dixon, L. J., Schlub, R. L., Pernezny, K., and Datnoff, L. E. (2009). Host specialization and phylogenetic diversity of Corynespora cassiicola. Phytopathology 99, 1015-1027. doi: 10.1094/PHYTO-99-9-1015

Du, Z., Zhou, X., Ling, Y., Zhang, Z., and Su, Z. (2010). agriGO: a GO analysis toolkit for the agricultural community. Nucleic Acids Res. 38, W64-W70. doi: 10.1093/nar/gkq310

Du Jardin, P. (2015). Plant biostimulants: definition, concept, main categories and regulation. Sci. Hortic. 196, 3-14. doi: 10.1016/j.scienta.2015.09.021

Feng, D. X., Tasset, C., Hanemian, M., Barlet, X., Hu, J., Trémousaygue, D., et al. (2012). Biological control of bacterial wilt in Arabidopsis thaliana involves abscissic acid signalling. New Phytol. 194, 1035-1045. doi: 10.1111/j.1469-8137.2012.04113.x

Feng, H., Xia, W., Shan, C., Zhou, T., Cai, W., and Zhang, W. (2015). Quaternized chitosan oligomers as novel elicitors inducing protection against B. cinerea in Arabidopsis. Int. J. Biol. Macromol. 72, 364-369. doi: 10.1016/j.ijbiomac.2014.06.060

Ferrari, S., Galletti, R., Denoux, C., De Lorenzo, G., Ausubel, F. M., and Dewdney, J. (2007). Resistance to Botrytis cinerea induced in Arabidopsis by elicitors is independent of salicylic acid, ethylene, or jasmonate signaling but requires phytoalexin deficient3. Plant Physiol. 144, 367-379. doi: 10.1104/pp.107.095596 
Ferrari, S., Plotnikova, J. M., De Lorenzo, G., and Ausubel, F. M. (2003). Arabidopsis local resistance to Botrytis cinerea involves salicylic acid and camalexin and requires EDS4 and PAD2, but not SID2, EDS5 or PAD4. Plant J. 35, 193-205. doi: 10.1046/j.1365-313X.2003.01794.x

Ferreira-Saab, M. (2018). Leveduras Como Antagonistas à Fitopatógenos da Soja e Indutor de Resistência, PhD Dissertation, Universidade Estadual de Maringá.

Fisher, M. C., Henk, D. A., Briggs, C. J., Brownstein, J. S., Madoff, L. C., Mccraw, S. L., et al. (2012). Emerging fungal threats to animal, plant and ecosystem health. Nature 484:186. doi: 10.1038/nature10947

Frey, P., Prior, P., Marie, C., Kotoujansky, A., Trigalet-Demery, D., and Trigalet, A. (1994). Hrp(-) mutants of Pseudomonas solanacearum as potential biocontrol agents of tomato bacterial wilt. Appl. Environ. Microbiol. 60, 3175-3181.

Garcion, C., Lamotte, O., and Métraux, J. P. (2007). "Mechanisms of defence to pathogens: biochemistry and physiology," in Induced Resistance for Plant Defence: A Sustainable Approach to Crop Protection, eds W. D. Newton and G. D. Lyon. (Oxford: Blackwell Press), 109-132.

Garcion, C., and Metraux, J. (2006). FiRe and microarrays: a fast answer to burning questions. Trends Plant Sci. 11, 320-322. doi: 10.1016/j.tplants.2006.05.009

Glazebrook, J. (2005). Contrasting mechanisms of defense against biotrophic and necrotrophic pathogens. Annu. Rev. Phytopathol. 43, 205-227. doi: 10.1146/annurev.phyto.43.040204.135923

Grant, M. R., and Jones, J. D. G. (2009). Hormone (Dis)harmony moulds plant health and disease. Science 324, 750-752. doi: 10.1126/science.1173771

Hael-Conrad, V., Abou-Mansour, E., Díaz-Ricci, J. C., Métraux, J. P., and Serrano, M. (2015). The novel elicitor AsES triggers a defense response against Botrytis cinerea in Arabidopsis thaliana. Plant Sci. 241, 120-127. doi: 10.1016/j.plantsci.2015.09.025

Hatoum, R., Labrie, S., and Fliss, I. (2012). Antimicrobial and probiotic properties of yeasts: from fundamental to novel applications. Front. Microbiol. 3:421. doi: $10.3389 /$ fmicb. 2012.00421

Katagiri, F., and Tsuda, K. (2010). Understanding the plant immune system. Mol. Plant-Microbe Interact. 23, 1531-1536. doi: 10.1094/MPMI-04-10-0099

Klessig, D. F., Choi, H. W., and Dempsey, D. A. (2018). Systemic acquired resistance and salicylic acid: past, present and future. Mol. Plant Microbe Interact. doi: 10.1094/MPMI-03-18-0067-CR. [Epub ahead of print].

Koornneef, A., and Pieterse, C. M. J. (2008). Cross talk in defense signaling. Plant Physiol. 146, 839-844. doi: 10.1104/pp.107.112029

Kroll, S., Agler, M. T., and Kemen, E. (2017). Genomic dissection of host-microbe and microbe-microbe interactions for advanced plant breeding. Curr. Opin. Plant Biol. 36, 71-78. doi: 10.1016/j.pbi.2017.01.004

Langmead, B., and Salzberg, S. L. (2012). Fast gapped-read alignment with Bowtie 2. Nat. Methods 9:357. doi: 10.1038/nmeth.1923

L'Haridon, F., Besson-Bard, A., Binda, M., Serrano, M., Abou-Mansour, E., Balet, F., et al. (2011). A permeable cuticle is associated with the release of reactive oxygen species and induction of innate immunity. PLoS Pathog. 7:e1002148. doi: 10.1371/journal.ppat.1002148

Li, B., and Dewey, C. N. (2011). RSEM: accurate transcript quantification from RNA-Seq data with or without a reference genome. BMC Bioinformatics 12:323. doi: 10.1186/1471-2105-12-323

Liu, J., Sui, Y., Wisniewski, M., Droby, S., and Liu, Y. (2013). Review: utilization of antagonistic yeasts to manage postharvest fungal diseases of fruit. Int. J. Food Microbiol. 167, 153-160. doi: 10.1016/j.ijfoodmicro.2013.09.004

Maffei, M. E., Arimura, G.-I., and Mithofer, A. (2012). Natural elicitors, effectors and modulators of plant responses. Nat. Product Rep. 29, 1288-1303. doi: 10.1039/c2np20053h

Manju, M., Benagi, V., Hanumaiah, S., Jacob, C. K., and P, S. I. (2014). Antifungal activity of some biological agents against Corynespora cassiicola causing Corynespora leaf fall disease of rubber (Hevea brasiliensis Muell. Arg.). Ind. J. Adv. Plant Res. 1, 30-32.

Massart, S., Perazzolli, M., Höfte, M., Pertot, I., and Jijakli, M. H. (2015). Impact of the omic technologies for understanding the modes of action of biological control agents against plant pathogens. BioControl 60, 725-746. doi: $10.1007 /$ s10526-015-9686-Z

Mishra, B., Sun, Y., Ahmed, H., Liu, X., and Mukhtar, M. S. (2017). Global temporal dynamic landscape of pathogen-mediated subversion of Arabidopsis innate immunity. Sci. Rep. 7:7849. doi: 10.1038/s41598-017-08073-z

Morán-Diez, E., Rubio, B., Domínguez, S., Hermosa, R., Monte, E., and Nicolás, C. (2012). Transcriptomic response of Arabidopsis thaliana after $24 \mathrm{~h}$ incubation with the biocontrol fungus Trichoderma harzianum. J. Plant Physiol. 169, 614-620. doi: 10.1016/j.jplph.2011.12.016

Nunes, C. A. (2012). Biological control of postharvest diseases of fruit. Eur. J. Plant Pathol. 133, 181-196. doi: 10.1007/s10658-011-9919-7

Nunes, C., Usall, J., Teixidó, N., Fons, E., and Viñas, I. (2002). Post-harvest biological control by Pantoea agglomerans (CPA-2) on golden delicious apples. J. Appl. Microbiol. 92, 247-255. doi: 10.1046/j.1365-2672.2002.01524.x

Papalexandratou, Z., Lefeber, T., Bahrim, B., Lee, O. S., Daniel, H.-M., and De Vuyst, L. (2013). Hanseniaspora opuntiae, Saccharomyces cerevisiae, Lactobacillus fermentum, and Acetobacter pasteurianus predominate during well-performed Malaysian cocoa bean box fermentations, underlining the importance of these microbial species for a successful cocoa bean fermentation process. Food Microbiol. 35, 73-85. doi: 10.1016/j.fm.2013.02.015

Pieterse, C. M., Leon-Reyes, A., Van Der Ent, S., and Van Wees, S. C. M. (2009). Networking by small-molecule hormones in plant immunity. Nat. Chem. Biol. 5, 308-316. doi: 10.1038/nchembio. 164

Ren, J. J., Shi, G. L., Wang, X. Q., Liu, J. G., and Wang, Y. N. (2013). Identification and characterization of a novel Bacillus subtilis strain with potent antifungal activity of a flagellin-like protein. World J. Microbiol. Biotechnol. 29, 2343-2352. doi: 10.1007/s11274-013-1401-6

Robert-Seilaniantz, A., Grant, M., and Jones, J. D. G. (2011). Hormone crosstalk in plant disease and defense: more than just jasmonatesalicylate Antagonism. Annu. Rev. Phytopathol. 49, 317-343. doi: 10.1146/annurev-phyto-073009-114447

Sanchez, L., Courteaux, B., Hubert, J., Kauffmann, S., Renault, J.-H., Clément, C., et al. (2012). Rhamnolipids elicit defense responses and induce disease resistance against biotrophic, hemibiotrophic, and necrotrophic pathogens that require different signaling pathways in Arabidopsis and highlight a central role for salicylic acid. Plant Physiol. 160, 1630-1641. doi: 10.1104/pp.112. 201913

Schmittgen, T. D., and Livak, K. J. (2008). Analyzing real-time PCR data by the comparative CT method. Nat. Protocols 3, 1101-1108. doi: $10.1038 /$ nprot.2008.73

Serrano, M., and Guzmán, P. (2004). Isolation and gene expression analysis of Arabidopsis thaliana mutants with constitutive expression of ATL2, an early elicitor-response RING-H2 zinc-finger gene. Genetics 167, 919-929. doi: 10.1534/genetics.104.028043

Shrestha, S. K., Lamour, K., and Young-Kelly, H. (2017). Genome sequences and SNP analyses of Corynespora cassiicola from cotton and soybean in the southeastern United States reveal limited diversity. PLOS ONE 12:e0184908. doi: 10.1371/journal.pone.0184908

Soares, R. M., Godoy, C. V., and de Oliveira, M. C. N. (2009). Escala diagramática para avaliação da severidade da mancha alvo da soja. Trop. Plant Pathol. 34, 333-338. doi: 10.1590/S1982-56762009000500007

Thomma, B. P., Penninckx, I. A., Broekaert, W. F., and Cammue, B. P. (2001). The complexity of disease signaling in Arabidopsis. Curr. Opin. Immunol. 13, 63-68. doi: 10.1016/S0952-7915(00)00183-7

Trotel-Aziz, P., Couderchet, M., Vernet, G., and Aziz, A. (2006). Chitosan stimulates defense reactions in grapevine leaves and inhibits development of Botrytis cinerea. Eur. J. Plant Pathol. 114, 405-413. doi: 10.1007/s10658-006-0005-5

Tsuda, K., and Somssich, I. E. (2015). Transcriptional networks in plant immunity. New Phytol. 206, 932-947. doi: 10.1111/nph.13286

Van Kan, J. A., Stassen, J. H., Mosbach, A., Van Der Lee, T. A., Faino, L., Farmer, A. D. et al. (2017). A gapless genome sequence of the fungus Botrytis cinerea. Mol. Plant Pathol. 18, 75-89. doi: 10.1111/mpp.12384

Verhage, A., van Wees, S. C. M., and Pieterse, C. M. J. (2010). Plant immunity: it's the hormones talking, but what do they say? Plant Physiol. 154, 536-540. doi: 10.1104/pp.110.161570

Wang, L., Feng, Z., Wang, X., Wang, X., and Zhang, X. (2010). DEGseq: an $\mathrm{R}$ package for identifying differentially expressed genes from RNA-seq data. Bioinformatics 26, 136-138. doi: 10.1093/bioinformatics/btp612

Wiesel, L., Newton, A. C., Elliott, I., Booty, D., Gilroy, E. M., Birch, P. R. J., et al. (2014). Molecular effects of resistance elicitors from biological origin and their potential for crop protection. Front. Plant Sci. 5:655. doi: 10.3389/fpls.2014.00655

Windram, O., Madhou, P., Mchattie, S., Hill, C., Hickman, R., Cooke, E., et al. (2012). Arabidopsis defense against Botrytis cinerea: chronology and regulation 
deciphered by high-resolution temporal transcriptomic analysis. Plant Cell 24, 3530-3557. doi: $10.1105 /$ tpc.112.102046

Yin, H., Du, Y., and Dong, Z. (2016). Chitin Oligosaccharide and Chitosan Oligosaccharide: two similar but different plant elicitors. Front. Plant Sci. 7:522. doi: $10.3389 /$ fpls.2016.00522

Zhang, Y., Yang, X., Zeng, H., Guo, L., Yuan, J., and Qiu, D. (2014). Fungal elicitor protein PebC1 from Botrytis cinerea improves disease resistance in Arabidopsis thaliana. Biotechnol. Lett. 36, 1069-1078. doi: 10.1007/s10529-0141462-0

Zipfel, C., and Oldroyd, G. E. (2017). Plant signalling in symbiosis and immunity. Nature 543, 328-336. doi: 10.1038/nature22009
Conflict of Interest Statement: The authors declare that the research was conducted in the absence of any commercial or financial relationships that could be construed as a potential conflict of interest.

Copyright (c) 2018 Ferreira-Saab, Formey, Torres, Aragón, Padilla, Tromas, Sohlenkamp, Schwan-Estrada and Serrano. This is an open-access article distributed under the terms of the Creative Commons Attribution License (CC BY). The use, distribution or reproduction in other forums is permitted, provided the original author(s) and the copyright owner(s) are credited and that the original publication in this journal is cited, in accordance with accepted academic practice. No use, distribution or reproduction is permitted which does not comply with these terms. 